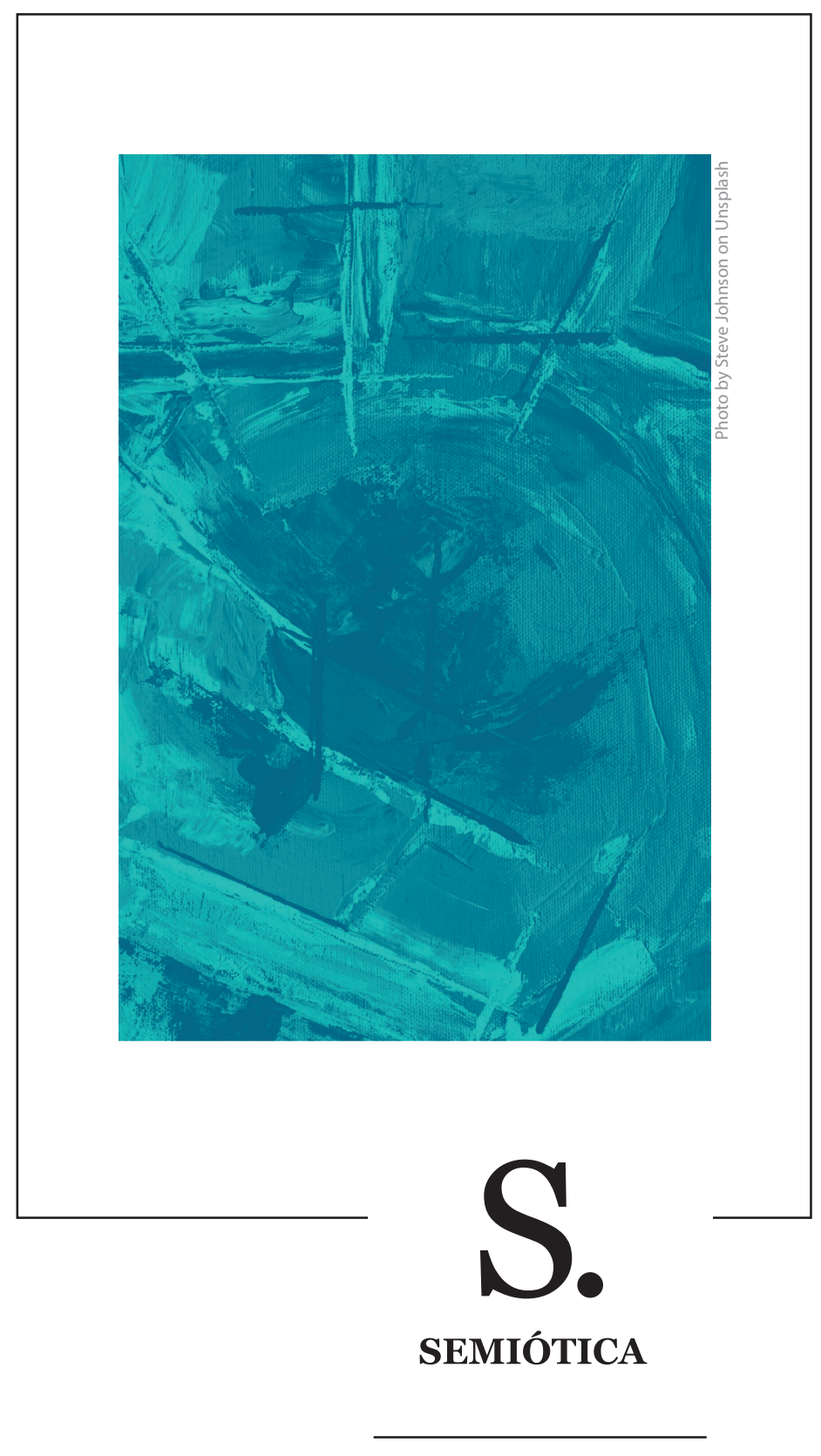




\title{
Cambio y fuera: del banquete a la bancarrota
}

\author{
Óscar Quezada Macchiavello
}

\section{Cuestión previa: la lógica de la acción}

Un banquete ofrecido por el protagonista al presidente de la república. En el esquema narrativo de la búsqueda, ese banquete figura como objeto modal de poder, no vale por sí mismo sino por lo que significa como medio-para. Llena el 'casillero' correspondiente a la competencia del sujeto con vistas a una performance que él mismo se ha propuesto cumplir'.

Siguiendo la norma clásica del género, la instancia de discurso, en cuanto narrador observador, cuenta una historia de la que está ausente, lo que no impide que se muestre en juicios de valor en torno a esas terceras personas observadas como actores natos. Parece que nadie habla, que todo 'se cuenta' solo. No obstante, por un lado, el efecto de 'realidad' es reforzado con embragues enunciativos, esto es, con simulacros de diálogo entre esos actores; por otro lado, es posible develar marcadores de actitud de ese narrador construido como testigo ante un espectáculo que lo encubre y revela a la vez como instancia de evaluación e interpretación axiológica. El cuento es 'llevar cuenta' de un hecho. Pero el hecho existe contante, sonante, contado, puesto a significar y significado por alguien. No hay hecho no significante. Algo ya pasó y 'continúa siendo' en palabras dichas o escritas.

Ahora bien, "la lógica de la acción se basa en una transformación discontinua de los estados de cosas. Una acción enlaza dos situaciones, la situación inicial y la situación final, cuyos contenidos respectivos están invertidos" (Fontanille, 2001, p. 165). Antes de la acción, el protagonista es carente, mejor dicho, no carece de carencias. Ambicioso, no está conforme con su situación. Quiere y no tiene una embajada en Europa y un ferrocarril a sus tierras de la montaña. No obstante, tiene recursos para obtener lo que se

1 El cuento que aquí se analiza es El banquete de Julio Ramón Ribeyro, publicado originalmente en Cuentos de circunstancias en 1958. El relato completo se puede encontrar en ciudadseva.com/texto/el-banquete 
propone. Después de la acción, realmente compleja en virtud de todo lo implicado por el objeto 'banquete', tiene la promesa del presidente para acceder al objeto de valor doblemente tematizado. Por lo mismo, cree haberlo obtenido, se siente realizado, merced a un exitoso contrato afectivo y fiduciario articulado en las dimensiones pasional y cognitiva del relato: cree que el presidente va a hacer algo para que él devenga conjunto con esos preciados objetos que hacen uno solo. Su espera fiduciaria está llena de optimismo. Presiente un final feliz. Pero ahí no termina el relato. Falta el nocaut final que sobreviene en la dimensión pragmática. En efecto, de modo muy condensado, el narrador, poniendo en escena el periódico del día siguiente, informa al enunciatario del discurso y a los actores protagonistas que, mientras asistía al banquete, el presidente había sido derrocado. En consecuencia, si superponemos la situación final a la inicial, encontramos que, en cierto modo, el protagonista ha sido castigado por los hechos: en términos de junción, sigue carente, aunque en mayor medida, pues ha gastado su fortuna en el malhadado banquete. Guiado por una motivación endotáctica (querer) y por una aptitud exotáctica (poder) había programado un aumento de su prestigio y de su poder poder más. Desear un objeto es imaginarse con él. A partir de ahí, su deseo, traducido en disposición imaginaria, pasional, le dicta una estrategia de conducta articulada por un interesado ritual de intercambio: ofrecer un fastuoso banquete al presidente, halagarlo, adularlo, para obtener, a cambio, esa añorada embajada y ese potente ferrocarril a sus tierras. En la lógica de la acción, de la programación narrativa, parte de lo nefasto final para arribar a los fastos previos. En la lógica de la propensión procesual, de la consecución discursiva, se sigue la ruta inversa. Veamos.

\section{PREPARATIVOS}

En efecto, el banquete es solo un medio para alcanzar esos objetos de mayor valor. En relación con mi práctica docente, este cuento resultaba explícito para poner en evidencia la imperfección de una programación aparentemente perfecta, la cual, a simple vista prevé todo lo previsible... sin contar, para nada, con algo tan impensable como imprevisto, esto es, con un evento mucho más breve, rotundo y eficaz que el esmerado plan relatado en casi todo el cuento. Las lógicas de la regularidad chocan con una de las jugadas de lo aleatorio. Tropiezan con un accidente, con una extraña coincidencia teñida de tragicómica ironía.

\section{Onomástica}

El protagonista se llama Fernando Pasamano, ese apellido es un guiño redondo del enunciador al enunciatario: crea una imagen precisa del actor. Tratándose de un esnob, entre arribista y huachafo, que, vía contrato, recurre a una estrategia de adulación para alcanzar sus fines, el término no puede ser más preciso: pasamano, en cuanto 
sustantivo, es la parte de la escalera (se entiende, en dirección ascendente) que sirve para apoyar las manos; en cuanto verbo, pasar la mano equivale a adular, o, en términos más coloquiales, a sobar a un poderoso con el objeto de conseguir una prebenda o una ventaja. En suma, Fernando Pasamano es un sobón, un trepador. En el relato es Don Fernando (DF): un impulsivo sin método. O, para precisar, con cierto método logrado en acto, a marcha forzada.

\section{Arquitectura / Albañilería}

La programación narrativa del relato, al ser convertida en temporalización discursiva, equivale a dos meses. Esa anticipación del 'magno suceso' hace de DF un sujeto calculador (por el título, el enunciatario asocia el 'magno suceso' con el 'banquete'). “En primer término, su residencia hubo de sufrir una transformación general" (Ribeyro, 1973, p. 111). No dice "casa", no dice "departamento". Dice "residencia", término que modaliza a DF como sujeto de poder: posee una residencia y cuenta con los medios para someterla a una "transformación general". Este último término condensa un aspecto importante de los preparativos para el banquete. Con vistas a dar cuenta de la elasticidad del discurso, vamos a la expansión de esa condensación: “Como se trataba de un caserón antiguo, fue necesario echar abajo algunos muros, agrandar las ventanas, cambiar la madera de los pisos y pintar de nuevo todas las paredes" (Ribeyro, 1973, p. 111).

Cada acción equivale a un subprograma narrativo que presupone otros, no necesariamente dichos, pero sí sugeridos. Se crea así una compleja jerarquía de programas presupuestos e implícitos, coordinados unos con otros, en unos casos concomitantes, en otros, no concomitantes, de acuerdo con la generación de coherencia. La acción se encadena en actos sucesivos y simultáneos.

Desde el momento en que se trata de un "caserón antiguo", el poder inicial de DF queda un tanto atenuado con vistas a dar cuenta de lo laborioso de la transformación $\mathrm{y}$, por tanto, de las complicaciones en las que DF se va involucrando. Sin duda, en su imaginario pasional ya ha cobrado forma una especie de 'fotografía' de lo que debe ser una residencia digna del 'magno suceso' por él programado.

\section{Mobiliario}

Previa anáfora condensadora, "Esta reforma", sigamos con la expansión, la cual cambia de isotopía pasando de la infraestructura de la residencia a su mobiliario:

Esta reforma trajo consigo otras y - como esas personas que cuando se compran un par de zapatos juzgan que es necesario estrenarlos con calcetines nuevos y luego con una camisa nueva y luego con un terno nuevo y así sucesivamente hasta llegar 
al calzoncillo nuevo- don Fernando se vio obligado a renovar todo el mobiliario, desde las consolas del salón hasta el último banco de la repostería. Luego vinieron las alfombras, las lámparas, las cortinas y los cuadros para cubrir esas paredes que desde que estaban limpias parecían más grandes. (Ribeyro, 1973, p. 111)

En lo que respecta a la transformación de su residencia, DF asocia ineluctablemente su poder con un deber ser, grabado, marcado, en su disposición pasional, imaginaria. Está dominado, controlado de modo irremisible, por la potencia de ese deber ser, por la imagen de esa residencia ideal que, automáticamente, lo va arrastrando, al extremo de renovar todo el mobiliario.

La inserción del símil de la vestimenta abre las puertas de un mundo posible, cuyo estereotipo son las personas que se van dejando llevar por sucesivas exigencias de renovación, hasta llegar al "calzoncillo nuevo". Esa nota humorística asimila a DF al personaje obsesivo, hechizado por su propio deseo, tan íntimo como la ropa interior.

\section{Jardinería}

La morfología del objeto-residencia, como un todo, explica que los subprogramas adopten una estructura de partes. Eso en lo relativo al espacio de acogida al presidente. En lo que respecta al tiempo, DF prevé un ceremonial que incluye un concierto en el jardín, lo que implica, de vuelta al espacio, ¡construir un jardín! Esa acción compacta, contrae la duración a quince días. Los sujetos operadores ("jardineros japoneses") transforman "una especie de huerta salvaje" en un "maravilloso jardín rococó". Como enunciatarios, podemos sentir el tempo acelerado y la brevedad de la proeza, con su respectiva iconización: "donde había cipreses tallados, caminitos sin salida, laguna de peces rojos, una gruta para las divinidades y un puente rústico de madera que cruzaba sobre un torrente imaginario" (Ribeyro, 1973, p. 111).

\section{Gastronomías}

"La confección del menú" es calificada por el narrador, en relación anafórica con la "transformación de la residencia", como "lo más grave". Merced a la figura de la comparación de este nuevo preparativo con aquel otro, todo lo anterior resulta atenuado, leve y sencillo. Sin duda, esta es una operación de aumento de la intensidad y de contraste: lo "grave" remite también a lo complicado. Una disquisición etnosemiótica permite confrontar a los "provenientes del interior" y a los "capitalinos". Estos, no dichos pero supuestos, están en el centro de la semiosfera (Señores-todo-el-mundo. Landowski, 2007, p. 56). Aquellos, como DF y su mujer, están en sus márgenes (esnobs). Colmar la distancia entre, por un lado, las "comilonas provinciales, en las cuales se mezcla la 
chicha con el whisky y se termina devorando los cuyes con la mano", (Ribeyro, 1973, p. 111) y, por otro lado, "un banquete al presidente"; resulta difícil pues se trata de un tránsito de lo mezclado a lo selecto. DF y su mujer no saben lo que deben hacer. Están confundidos respecto a lo que debe servirse (no ocupan la posición de ese impersonal identificado con la norma, cuyo emblema es el "capitalino"). Se ven obligados a recurrir a destinadores del saber deber hacer. Ensayo-error: "la parentela" (delegados de la provincia). Ensayo-éxito: "los principales hoteles y restaurantes de la ciudad" (delegados de la capital; $y$, por extensión, de lo internacional). Gracias a una "encuesta" estos informadores hacen posible una transformación cognitiva de DF: "pudo enterarse que existían manjares presidenciales y vinos preciosos que fue necesario encargar por avión a las viñas del mediodía" (Ribeyro, 1973, pp. 111-112). Pero no solo se trata de los objetos, se trata también de los sujetos, de sus costumbres y modales: una "comilona" no es lo mismo que un "banquete". La presencia cultural del Otro implica en DF y su mujer, el acicate de una alteridad a la que hay que "asimilarse" a toda costa, expresado en un continuo movimiento de exasperada alienación a todo costo.

\section{Angustia / Seguridad}

El sujeto ha cumplido escrupulosamente con todos esos preparativos, ha superado riesgos funcionales y, en lugar de relajarse, se angustia. No sabe en qué va a terminar su magno proyecto: una andanada de datos abre la dimensión cuantitativa de su estado pasional, al banquete "asistirían ciento cincuenta personas, cuarenta mozos de servicio, dos orquestas, un cuerpo de ballet y un operador de cine" (Ribeyro, 1973, p. 112). Se ha metido en algo grande. En la perspectiva enunciativa, todo deviene desmesurado, exagerado, hiperbólico. Sucesivos datos, aparte de estos últimos, han ido dando una idea de cómo DF "había invertido toda su fortuna" embarcado en una interacción bastante arriesgada. No obstante, en la perspectiva de DF "lo grande parece pequeño", confía en su gran maniobra. Afronta esa angustia con un sentimiento de seguridad en su apuesta: “[...] al fin de cuentas, todo dispendio le parecía pequeño para los enormes beneficios que obtendría de esa recepción" (Ribeyro, 1973, p. 112). En efecto, en las lógicas de la intencionalidad, más que un artista de la manipulación, de la labia, al menos hasta aquí, DF aparece como un guerrero de la manipulación, esto es, como un sujeto que maniobra, que hace cosas, que crea un mundo, un escenario ideal para cumplir con un sueño.

\section{Primer diálogo}

En ese escenario se instala el primer simulacro enunciativo. DF, rebosante de optimismo, espera rehacer su fortuna "en menos de lo que canta un gallo", una vez que el presidente le conceda su objeto de valor doblemente tematizado (embajada y ferrocarril). 
Cabe suponer que su fortuna está seriamente disminuida por el descomunal esfuerzo de organización del banquete; por lo tanto, su aspiración a recuperarla carga semánticamente el objeto de valor con una tematización ulterior que, simultáneamente, lo desplaza. Por el lado descriptivo básico, el exceso en el virtual adquirir, o tomar, se expresa en la avidez reiterativa por la embajada y el ferrocarril. Por el lado modal, el exceso en el actual gastar, en el dar de sí, se expresa como derroche, disipación, prodigalidad, pero eminentemente interesados. De ahí que la obsesión por recuperar lo gastado complemente su avaricia proyectándola a un momento futuro en el que, además de la embajada y el ferrocarril, tenga mucho más dinero del que tiene actualmente.

En efecto, la espera, en cuanto dispositivo pasional, reconvierte el objeto de valor en objeto modal: la embajada y el ferrocarril devienen medios para un nuevo fin, a saber, recuperar rápidamente su inversión en el banquete. Mejor dicho, hacer que ese gasto se convierta en inversión. El canto del gallo no es solo emblema de brevedad, también es símbolo del amanecer a una nueva época de su vida. En el contraste entre lo descrito por el narrador y lo afirmado por el personaje ("Yo no pido más. Soy un hombre modesto.") queda configurada la ironía. La enunciación no asume lo afirmado por DF. El comentario de la mujer respecto al no saber aún si el presidente vendrá informa que DF “había omitido hasta el momento hacer efectiva la invitación" (Ribeyro, 1973, p. 112) y cataliza la siguiente secuencia.

\section{INVITACIÓN}

DF sabe que es pariente del presidente. Un nuevo comentario etnosemiótico, esta vez entre barras, que es lo mismo que 'entre líneas' o 'por lo bajo', da profundidad temporal al relato y lo tiñe con un toque de oscuro sarcasmo a modo de murmuración: "-con uno de esos parentescos serranos tan vagos como indemostrables y que, por lo general, nunca se esclarecen por temor de encontrarles un origen adulterino-" (Ribeyro, 1973, p. 112). Por contraste, el narrador no es serrano sino capitalino; reaparece así la semiosfera descrita líneas arriba. Solo que, esta vez, añade la promiscuidad sexual a costumbres como mezclar chicha con whisky y devorar los cuyes con la mano. En realidad, seguimos en el mundo de lo mezclado informal visto desde lo selecto formal. Mundo aquel, por temor, no esclarecido. El caso es que ese secreto saber da a DF plena seguridad respecto a la aceptación del presidente. Aunque seguro, DF, "para mayor seguridad, aprovechó su primera visita a palacio para conducir al presidente a un rincón y comunicarle humildemente su proyecto" (Ribeyro, 1973, p. 112). Lo secreto llama a lo secreto. Secreta, segrega (conducir a un rincón). La humildad, en este caso, es una figura de calculada sumisión. El presidente, "encantado", adelanta su aceptación, pero crea suspenso respecto a 
su confirmación "por escrito", pues se encuentra "muy ocupado". La comunicación del regido es oral, la del regente, escrita. Sutil alusión a la burocratización de las relaciones con el poder político.

\section{Impaciencia / Afectación}

La paciencia es saber esperar. La impaciencia, no saber esperar. Por lo demás, esperar quieto, tranquilo, sin hacer nada, alarga el tiempo de espera. Si no se sabe esperar, no se puede estar sin hacer nada. Hay que inquietarse, moverse, hacer algo para acortar y llenar el tiempo de espera. De ahí que, para distraerse, DF “ordenó algunas reformas suplementarias que dieron a su mansión el aspecto de un palacio afectado para una solemne mascarada" (Ribeyro, 1973, p. 112). A estas alturas, el enunciatario ya se ha acostumbrado a un estado de cosas manejado por DF, cuya expresión más concisa es "ordenar reformas". Esta vez, se trata de un nuevo argumento en virtud del cual cruza un umbral. La diátesis enunciativa predispone al lector a tomar distancia crítica del protagonista; no solo a no identificarse con él sino a sancionarlo axiológicamente como huachafo, esto es, como esnobista ingenuo, cursi, adocenado, atragantado por un exceso expresivo que él mismo no comprende. La residencia deviene mansión. La mansión deviene "palacio". Pero "palacio afectado", próximo a lo kitsch, es decir a la imitación por la imitación misma, a lo no genuino, a lo sucedáneo, a lo impropio. En su intenso deseo de aparentar lo que no es, DF realiza operaciones de fingimiento, de pretenciosa farsa. A la vista del observador, está montando una especie de rimbombante parodia. La cereza que, como "última idea", corona las reformas, consiste en "ordenar la ejecución de un retrato del presidente - que un pintor copió de una fotografía- y que él hizo colocar en la parte más visible de su salón" (Ribeyro, 1973, p. 112). La pintura sobre la fotografía remite a una estética híbrida, típica del interior del país, específicamente de la sierra. Por lo demás, esa práctica remite a la inveterada costumbre de funcionarios de todo nivel que consiste en colocar en las oficinas públicas la imagen del presidente de turno para congraciarse con él: retrato de plano medio, con la banda cruzando el pecho. Su salón se convierte así en lugar de culto, en templo que rinde pleitesía a la imagen de la imagen del presidente.

\section{Confirmación / Alucinación}

La espera duró "cuatro semanas". La confirmación fue, para DF, "la más grande alegría de su vida". Da lugar a "un día de fiesta, una especie de anticipo del festín que se aproximaba" (Ribeyro, 1973, p. 112). Sabor de inminente recompensa, sensación de premio por tanto desvelo, por tanta preocupación, por tanta reforma. Prueba glorificante, diría Propp, pero ansiosamente adelantada. La grata noticia y su correlato celebratorio despiertan la sensibilidad de los actantes centrales de este drama. Los objetos de valor se 
transmutan en presencias próximas que afectan a los cuerpos de los sujetos, que acelera sus ritmos. Luego, el sobresalto de la buena nueva es superado, la disposición pasional permite a DF imaginar el escenario de su victoria. "Salió con su mujer al balcón para contemplar su jardín iluminado y cerrar con un sueño bucólico esa memorable jornada" (Ribeyro, 1973, pp. 111-112). Espera relajarse, dormir, descansar. Lo bucólico evoca de modo idealizado el campo o la vida de campo (DRAE). DF vive en la ciudad, pero viene del interior. Un sueño así remite a la infancia como a una edad de oro, e incluso al seno materno. Deviene sueño nutricio, pensando en la otra acepción de bucólico (DRAE).

No obstante, al contemplar el jardín, éste "parecía haber perdido sus propiedades sensibles" (Ribeyro, 1973, p. 113). Esa desensibilización del jardín no solo es huella del narrador omnisciente que, en cuanto observador, ve desde el interior de su personaje. Señala también la causa de esa pérdida de propiedades sensibles del jardín: el estado de alma de DF es tan obseso y ansioso que el jardín, en cuanto estado de cosas, se convierte en espejo de su avidez y de sus más reprimidos deseos sexuales. El dispositivo pasional hace vibrar, paroxístico, el motor de lo imaginario. DF se alucina a sí mismo, en primer plano, como en tres posturas y vestimentas "con una decoración de fondo donde - como en ciertos afiches turísticos- se confundían los monumentos de las cuatro ciudades más importantes de Europa" (Ribeyro, 1973, p. 113). El símil de los afiches da cuenta de una imaginación estereotipada, de una iconografía que lo domina. El caso es que ya se ve a sí mismo en Europa. "Más lejos, en un ángulo de su quimera, veía un ferrocarril regresando de la floresta con sus vagones cargados de oro". En segundo plano, el otro componente del objeto de valor; pero, esta vez, el ferrocarril regresa a la capital "con sus vagones cargados de oro". La imagen misma de su enriquecimiento y de la recuperación, con creces, de su fortuna. Y, simbólicamente, de su conquista de la capital. Ahora bien, "por todo sitio", es decir, como clima o atmósfera de la alucinación, "movediza y transparente como una alegoría de la sensualidad, veía una figura femenina que tenía las piernas de una cocotte, el sombrero de una marquesa, los ojos de una tahitiana y absolutamente nada de su mujer" (Ribeyro, 1973, p. 113). Descripción realmente cómica por la figura de exclusión de "su mujer" que insufla a la ambición de DF un halo de lujuria y de potencial infidelidad: la antítesis misma de "su mujer" (aunque también sea mujer). En este pasaje, paisaje, paraje, de tónica alucinatoria, la narración hace gala de un potente imaginario cinematográfico, esto es, de una iconografía movediza que alude a sutiles transparencias entre las figuras evocadas.

\section{EL DÍA DEL BANQUETE}

Los "soplones" son la avanzada del aparato de inteligencia y seguridad del Estado. Si bien aparecen como queriendo pasar desapercibidos, el narrador, en cuanto observador, 
simula su delación y captación. Se trata de presencias "públicamente secretas" que no resisten la indiscreción de los observadores competentes que ya conocen sus gestos, modales e indumentarias. Tienen ese "aire de delincuencia" de "todos los que desempeñan oficios clandestinos": quieren parecer lo que no son y terminan pareciendo lo que son.

"Luego fueron llegando los automóviles". Estamos ante las figuras de una tradicional ceremonia de recibimiento de dignidades diplomáticas, políticas, empresariales y "de hombres inteligentes", típica escena protocolar del cine o del mundo del espectáculo: "Un portero les abría la verja, un ujier los anunciaba, un valet recibía sus prendas y don Fernando, en medio del vestíbulo, les estrechaba la mano, murmurando frases corteses y conmovidas" (Ribeyro, 1973, p. 113). División del trabajo o, mejor dicho, segmentación de roles temáticos en función de un recorrido establecido por la práctica. En efecto, la instancia de discurso supone un saber potencial sobre predicados temáticos (las 'visitas de Estado') aplicado a este relato concreto en acto. La eficiencia del deber hacer está regulada, desde el exterior de la praxis, por reglas conocidas que se imponen a todos los participantes. El narrador se ubica en la posición de evaluación externa, junto a "todos los burgueses del vecindario". Esos actores del contorno (a los que se suma "la gente de los conventillos") son asistentes que enfatizan el carácter espectacular de la recepción al banquete (que será reforzado, ya en la escena, por los edecanes del presidente).

Hasta que llega el sujeto puesto en la mira. Ese acontecimiento da lugar a la interferencia de la conducta de DF en los cánones de la ceremonia de recibimiento. Regida por el querer hacer, la conducta del oferente está movida por valores propios, individuales; obvian "las reglas de etiqueta", catalizan la ruptura de protocolos: así, DF, ante el presidente, "movido por un impulso de compadre, se le echó en los brazos con tanta simpatía que le dañó una de sus charreteras" (Ribeyro, 1973, pp. 113-114). La sombra de la "comilona de la provincia" y del oscuro parentesco se cierne sobre las luminarias del "banquete de mundo", tan escrupulosamente programado. El apunte final, referido a la graciosa anécdota de las charreteras, tal como el de la tahitiana y muchos otros, cumplen la función de acentos cómicos diseminados en la modulación misma del discurso

[...] en la comedia los personajes actúan para imitar los caracteres y, de este modo, no pueden asumir sus acciones, que resultan éticamente inimputables (por ello Aristóteles, en la Ética nicomaquea, puede escribir que en la comedia no está en cuestión, como en la tragedia, una culpa - hamartía-, sino dado que su elemento es lo ridículo, solo hay un hamártema, término que designa una culpa leve y no intencional). (Agamben, 2018, p. 78)

En efecto, estudiando a Aristóteles, Agamben nos ayuda a ponderar la ridiculez de DF: su vida no está determinada por la acción misma que con tanta pompa está 
gestionando y en la que residirá su tragedia. Es un inimputable, un inocente que elude asumir la acción sancionada desde la enunciación; es, en suma, un mimo, un modelo que representa el carácter de un audaz arribista. En esta ética cómica que el relato va hilando mediante acentos que son enfoques (zoom in, se diría en lenguaje audiovisual), la acción misma queda, por momentos, en segundo plano: una presencia irreductible en el fondo de toda la cadena de actividades narradas, un modo de ser y de comportarse, un carácter, prima finalmente en el tratamiento mismo del relato.

El observador 'entra' a la residencia para certificar cómo el actor colectivo, constituido por los participantes invitados al banquete, consume y consuma las mercancías adquiridas por DF. Por lo pronto, "entre chistes y epigramas, los cuarenta cajones de whisky". De la hipérbole de la compra a la del consumo. Del hablar impregnado de comicidad, ingenio y argucia, al beber desenfrenado; y de ahí, a comer:

Luego se acomodaron en las mesas que les estaban reservadas -la más grande, decorada con orquídeas, fue ocupada por el presidente y los hombres ejemplaresy se comenzó a comer y charlar ruidosamente mientras la orquesta, en un ángulo del salón, trataba inútilmente de imponer un aire vienés. (Ribeyro, 1973, p. 114)

La acomodación, en este caso, equivale a una toma de posición en ese dispositivo clientelista de control social que son las mesas de un banquete: en este caso, el tamaño y la decoración son códigos que marcan una jerarquía cuya cima está ocupada por la máxima autoridad política y los sujetos que, por una razón u otra, ofician como parangones sociales dignos de imitación y cuya sima está poblada por servilismos de distinto jaez. El tamaño de la mesa señala una coherencia conversa: el objeto más grande para los sujetos más grandes; y la decoración remite a "las orquídeas", las cuales, más allá de su peso simbólico o convencional, asociadas con la delicadeza y con lo más caro, valen por su presencia en esa mesa y su ausencia en las otras: encarnan, pues, como valor de absoluto, la distinción del poder.

El valor de tres prácticas, a saber: la comida, la conversación y la música de acompañamiento, depende de su articulación común, las dos primeras van unidas en concomitancia: los actores hablan mientras comen. El escenario sonoro, relevado por la descripción, indica que la charla es tan ruidosa que domina a la música, al extremo de que ésta pasa a ser de fondo. Esa incompetencia de la orquesta para imponer volumen, confinada "en un ángulo del salón", se convierte en otro acento cómico, exacerbado por el "aire vienés" emitido en abismo, casi ausente. Deviene símbolo agazapado de la "embajada en Europa", aun en horizonte, cubierta por la cháchara de la clase política nacional. El fracaso en la complementación de charla y música es un signo de incongruencia en la pretendida programación del banquete: a la gente le interesa más escucharse a sí misma que escuchar esa música "que viene de otra parte". El régimen de 
sensibilidad de los invitados se impone a la regulación teórica de la reunión propuesta por DF como organizador. Después de todo, el banquete solo vale por la ocasión a la que va a dar lugar, es decir, por la intencionalidad que oculta. En la siguiente secuencia:

A mitad del banquete, cuando los vinos blancos del Rhin habían sido honrados y los tintos del Mediterráneo comenzaban a llenar las copas, se inició la ronda de discursos. La llegada del faisán los interrumpió y solo al final, servido el champán, regresó la elocuencia y los panegíricos se prolongaron hasta el café, para ahogarse en las copas de coñac. (Ribeyro, 1973, p. 114)

Los discursos aparecen como una especie de organismo vivo que nace con los vinos, entra en letargo con la comida, resurge con el champán y se ahoga en el coñac. La palabra, lubricada por las bebidas alcohólicas, marca la pauta de segmentación del ritual de la comida. Faisán rima con champán, son emblemas de prácticas que también riman. Al menos en una visión de conjunto, hay conexión y equilibrio entre las prácticas. "El valor reside, pues, no solamente en la calidad de la conexión, sino precisamente en la capacidad de esa articulación para exhibirse a sí misma y para hacerse conocer a los participantes, como sucede en el ritual" (Fontanille, 2014, p. 173). El faisán, por su rareza y esplendor, es un valor de absoluto, irrumpe, interrumpe; el champán, por su carácter común y su prestigio, es un valor del universo, francés, europeo, incita a la expansión retórica. Por lo demás, en plena sensibilidad dionisiaca, el panegírico, como género discursivo que propende al encomio, el elogio y la alabanza, crea un clima de honor, de fervor, una esfera de adulación, que se inscribe perfectamente en la estrategia de DF. El panegírico se perfila, pues, como prueba de elocuencia: los participantes se miden, unos destacan más que otros y, entre todos, se enardecen pues están eufóricos por los excesos. La secuencia es pertinente: una comida ordenada, completa, "bien regada”, una prueba discursiva en buena y debida forma; funcionan "como una semiótica connotativa, donde una de las dos prácticas (hablar) confirma y fija reflexivamente la canonicidad de la otra (comer)." (Fontanille, 2014, p. 175). Sin duda, para hablar hay que interrumpir la comida, hablar pide al otro escuchar y llama su atención, es decir, establece una síncopa rítmica respecto a la segmentación canónica. Pero en estos rituales la interrupción está prevista, llama y no llama la atención pues las secuencias de 'hacer discursos' y de 'comer/beber' son sincrónicas, entonces la secuencia de los oradores "expresa reflexivamente la buena forma del protocolo". (Fontanille, 2014, p. 175)

Fontanille recuerda que

[...] la relación entre la secuencia alimentaria y la secuencia conversacional es reflexiva pero disimétrica: (i) la segunda refleja la primera, la comenta, la refuerza, la dobla de manera redundante y sincrónica, y (ii) la primera proporciona a la segunda un marco relativamente estable. [...] la secuencia alimentaria, en cuanto protocolo, está regulada por usos culturales, y no se decide en el momento mismo 
de la comida; por innovadora que sea, debe ser regulada y decidida de antemano. En cambio, la secuencia conversacional, en cuanto conducta, no está generalmente planificada, y aunque obedezca a algunas reglas culturales, su forma general debe ser inventada en tiempo real por medio de un ajuste estratégico permanente. (Fontanille, 2014, p. 177)

Landowski confirmaría, en su teoría sobre los regímenes de interacción, que el protocolo es una programación y la conversación un ajuste.

Los momentos de sincronización, como el de esta secuencia, en cuanto nudos axiológicos, logran involucrar a los participantes en una estrategia colectiva bañada de cordialidad. Al menos eso parece. Se supone que los participantes reaccionan a esa buena forma, son sensibles a ese modo de darse las cosas, a esa cosegmentación de prácticas: la cordialidad surge como resultado de la percepción de acomodación entre las secuencias de charla y trago, de charla y comida; y de discursos con trago y comida. En suma, se impone el coajuste de los participantes, la sintonía de sensibilidades, "el banquete, pleno de salud ya, seguía sus propias leyes", hacía sentido por sí mismo por encima de la insignificancia de los rituales convenidos. Esa tensión de dominación del ajuste sobre la programación tiene inquieto a DF, quien no encuentra la "ocasión de hacerle al presidente sus confidencias". Es decir, para insertar, entre una y otro, una manipulación. La dinámica sensible del banquete se ha acelerado al máximo ("pleno de salud" tiene dos sentidos: sanidad y brindis). El festín es un ámbito de contagios corporales, de contactos directos que suprimen distancias. DF, lo hemos visto ya en la escena de recepción al presidente, privilegia su conducta sobre cualquier protocolo; empero, esa vida propia del festín empieza a incomodarlo: "A pesar de haberse sentado, contra las reglas del protocolo, a la izquierda del agasajado, no encontraba el instante propicio para hacer un aparte" (Ribeyro, 1973, p. 114). En efecto, el régimen de ajuste no solo altera la programación básica de DF, además pone trabas a su proyecto de comunicación privada con el presidente, o sea, de íntima manipulación al mandatario.

Para colmo, terminado el servicio los comensales se levantaron para formar grupos amodorrados y digestónicos y él, en su papel de anfitrión, se vio obligado a correr de grupo en grupo para reanimarlos con copas de menta, palmaditas, puros y paradojas. (Ribeyro, 1973, p. 114)

El metalenguaje de los más y los menos, empleado por Zilberberg para dar cuenta de la ascendencia y descendencia tensivas, puede ser adecuado, en este caso, para imaginar ajustes, reajustes y desajustes sensibles, oscilantes, en tensión con programaciones que quieren asegurar regularidad, esto es, la estática y dinámica del banquete como "ser viviente en un entorno" (Zilberbeg, 2015, p. 73, 115). Ha habido cada vez más de más, lo que Zilberberg llama redoblamiento (compuesto de progresión: añadido de al menos un más; y de saturación: añadido de más de un más). Pero cuando "los comensales 
se levantaron" aparecen los signos de cansancio y pesadez estomacal. La congregación empieza a disgregarse en súbita y disfórica atenuación (cada vez menos de más). DF se ve obligado a reanimar a la gente, pues es evidente que el ánimo ha disminuido. Debe poner en práctica su rol de anfitrión manipulador, como si estuviese entrenando para la manipulación decisiva que le espera. Ese "correr de grupo en grupo", signo de tempo acelerado, pretende contrarrestar los componentes tensivos de la atenuación (moderación: retiro de al menos un más; y disminución: retiro de más de un más). Queda clara esa idea del banquete como "ser viviente, sensible": la reanimación que DF pretende, presupone una inconveniente cadena de moderación y disminución del ánimo, es decir, una atenuación frente a la cual solo queda una estrategia de repunte (cada vez menos de menos). Emprende, pues, una reanudación: retiro de al menos un menos; y una progresión: retiro de más de un menos; cuyas cuatro figuras devienen, de nuevo, por su genial combinación, acentos cómicos. Cada una convoca una isotopía: copas de menta (gusto, sabor, dulzor, frescura), palmaditas (tacto, suavidad, cercanía), puros (gusto, sabor, calor, tabaco) y paradojas (habla, juego de lenguaje, intelecto).

[El enunciador literario nos recuerda aquí que la escritura, como código vicario, representa sonidos. El fonema $|p|$, presente en los cuatro elementos, inicia los tres últimos, da la pauta rítmica de la serie; pero la explosión semántica está en el contraste del último término, abstracto, con los tres anteriores, concretos. En especial, con el más cercano: el encuentro de "puros" y "paradojas" (que podría condensarse lúdicamente en "purodojas"). En esta breve lista, la mencionada aliteración y sus efectos nos recuerdan que un narrador no tiene por qué no ser un eximio poeta.]

El relato no señala explícitamente a qué hora empezó la reunión, el enunciatario solo sabe que todo comenzó en algún momento después de las cinco de la tarde. Pues bien, todo organismo vivo muere. La descendencia o, mejor, decadencia, es inevitable: se trata de una aminoración (cada vez más de menos) por reducción, añadido de al menos un menos; y, finalmente, por extenuación, añadido de más de un menos.

Al fin, cerca de la medianoche, cuando el ministro de gobierno, ebrio, se había visto forzado a una aparatosa retirada, don Fernando logró conducir al presidente a la salita de música y allí, sentados en uno de esos canapés que en la corte de Versalles servían para declararse a una princesa o para desbaratar una coalición, le deslizó al oído su modesta demanda. (Ribeyro, 1973, p. 114)

La cantidad de invitados ha ido mermando, de menos en menos. El ministro de gobierno, en total desgobierno de sí mismo, se ha ido. Se dan las condiciones para la fase persuasiva de la manipulación. Hasta el momento de conducir al presidente a la "salita de música", DF ha creado un ambiente; ha sido, como dijimos, un guerrero de la manipulación que ha operado por maniobras simultáneas y sucesivas. Este es el instante en el que aparece el artista de la manipulación, el persuasor, para quien ha 
sido preparada toda esa escenografía. DF, en la "salita de música", hace sonar su deseo suavemente, deslizándolo al oído del presidente. Eso de "modesta demanda" entraña algo de empatía del narrador con la mitomanía del personaje; pero, sin duda, es una ironía, una figura de distancia enunciativa. Por lo demás, la referencia a los "canapés" no solo es enciclopédica respecto a la memoria del relato. En efecto, el canapé remite a la "corte de Versalles"; es el objeto-huella de una oligarquía que remite a prácticas amorosas y políticas, pero también es una figura que actualiza Europa, aquel continente de la añorada embajada. La Francia de Versalles, del Rey Sol, de la monarquía absoluta, es un emblema que sintetiza los valores básicos deseados por DF: dominio extenso (en sus tierras de la montaña), lujo, brillo, poder.

La manipulación ha sido exitosa. Su escrupulosa ejecución ha hecho que el presidente decida aceptar los dos pedidos de DF. No solo le ofrece, de inmediato, la embajada en Roma que "Justamente queda vacante en estos días". Como eco de las figuras del absolutismo añade: "Mañana, en consejo de ministros, propondré su nombramiento, es decir, lo impondré". Está visto que es un presidente despótico, dictatorial, pues, además, "en lo que se refiere al ferrocarril", trata a los diputados como secretarios: "Pasado mañana citaré a mi despacho a todos sus miembros, y a usted también, para que resuelvan el asunto en la forma que más convenga" (Ribeyro, 1973, pp. 114-115). Corroborado: puede citar a toda la cámara de diputados para darles una orden. En los dos siguientes días DF realizaría su sueño. Entonces, el presidente ha decidido aceptar las "modestas demandas" de DF. Todo el banquete, a posteriori, se llena de sentido, de significación. La promesa ha sido dada en los mejores términos. Se podría decir, siguiendo la lógica aleatoria, probabilística, del accidente, que DF es un hombre de buena suerte. Su pedido ha estado marcado por el kairós, a saber, por la oportunidad. Pero siempre hay un tramo entre decidir y ejecutar. La decisión, en cuanto promesa, se inscribe en las lógicas cognitivas y pasionales de la intencionalidad. La ejecución se inscribe en otras lógicas, más bien pragmáticas, las de la regularidad.

La decisión: DF, con sus motivaciones (querer/deber) y sus aptitudes (saber/poder), ha afectado las motivaciones (querer/deber) y aptitudes (saber/poder) del presidente. Se ha sellado el pacto entre un presidente personalista y un experto halagador de sus vanidades y placeres. Estamos en un universo de competencias modales que se comunican y desembocan en un contrato: parafraseando, a cambio de tu lealtad te concedo tus pedidos. El presidente no solo concede las promesas, las reitera y se retira una hora después, seguido por su séquito de funcionarios "en el orden preestablecido por los usos y costumbres". La residencia queda casi vacía. El banquete está exhausto. La descripción produce un efecto de espaciosidad. "A las dos de la mañana quedaban todavía merodeando por el bar algunos cortesanos que no ostentaban ningún título y que esperaban aún el descorchamiento de alguna botella o la ocasión de llevarse a 
hurtadillas un cenicero de plata" (Ribeyro, 1973, p. 115). El narrador, en cuanto observador invisible, es un cronista de costumbres: se trata de actores secundarios que representan a los residuos o restos de toda reunión; la remisión a los cortesanos sin título hace resonar la historia como algo versallesco, pero, a la vez, como acento tragicómico puesto en dos vicios humanos universales: la borrachera y el robo.

"Solamente a las tres de la mañana quedaron solos Don Fernando y su mujer. Cambiando impresiones, haciendo auspiciosos proyectos, permanecieron hasta el alba entre los despojos de su inmenso festín" (Ribeyro, 1973, p. 115). El banquete ha muerto. Solo quedan sus despojos. Está en cero en cuanto festín, pero ha abierto un mundo de posibilidades y de potencialidades que entretiene a DF y su mujer "hasta el alba" llenándolos de ilusiones dictadas por sus simulacros pasionales.

\section{NOCAUT}

En las dimensiones pasional y cognitiva, para DF y su mujer, todo ha salido de maravilla. Ha habido simpatía, empatía, buena comunicación, promesa. Sensibilidades e intencionalidades han armonizado. Solo faltaba, en la dimensión pragmática, que todo siga su curso regular, esto es, que el presidente haga efectivo lo prometido. Los anfitriones del banquete daban por hecha la ejecución de lo decidido por el presidente. Pero, luego de ese arduo ejercicio de dos meses, siempre desde la perspectiva narrativa de la célula formada por DF y su mujer, sobreviene un evento absolutamente irregular, inesperado. "A las doce del día", DF es sometido a un despertar con sobresalto sonoro: "los gritos de su mujer". Ella es la mensajera del mensajero, a saber, del periódico abierto "entre las manos". "Arrebatándoselo, leyó los titulares y, sin proferir una exclamación, se desvaneció sobre la cama". DF ni siquiera está en capacidad de exclamar. Su carne misma es una interjección que lo tumba. "En la madrugada, aprovechándose de la recepción, un ministro había dado un golpe de estado y el presidente había sido obligado a dimitir" (Ribeyro, 1973, p. 115). El expresidente ya no puede hacer lo que DF le había hecho querer. Moralización: un contrato implica una acción, no su cumplimiento. La regularidad prevista por DF y su mujer, determinada por su exitosa intencionalidad manipuladora, es interrumpida por una tremenda noticia que, en la lógica aleatoria, equivale al accidente o al evento: quien parecía un hombre de buena suerte pasa, de golpe, a ser un hombre de muy mala suerte. En postura de muerte.

[A propósito del soterrado contraprograma del "golpe de estado" que, en términos estratégicos, neutraliza y anula brutalmente el programa de DF y su mujer, alguna estudiante, perspicaz, señalaba que "el ministro de gobierno, ebrio, se había visto forzado a una aparatosa retirada" (Ribeyro, 1973, p. 114) antes de la medianoche y lo sindicaba como el golpista. Yo le contestaba que, sin duda, su interpretación, basada 
en el texto, era coherente y que, además, daba un toque bufo a todo el psicodrama: un ministro borracho da un golpe de estado. La estudiante, para insuflar verosimilitud a su lectura, decía que el trago era un factor etílico que el felón empleó para "anestesiarse y darse fuerza" con vistas a emprender la traición al presidente. Por otro lado, cuando el presidente se retiraba, "lo siguieron sus ministros (...) de acuerdo con lo establecido por los usos y costumbres" (Ribeyro, 1973, p. 115). Ese "ministro de gobierno" sería, pues, el único que no había seguido "los usos y costumbres". Se retiró justo cuando comenzaba la madrugada, y el golpe fue en la madrugada. Como se ve, todos los elementos del texto apoyarían esa lectura. Empero, también dejan abierta la interpretación para alguna otra lectura, pues los ministros que siguieron "los usos y costumbres" se retiraron una hora después que el ebrio y dispusieron también de la madrugada para planificar y realizar la deposición del presidente. Este es, pues, un texto modelo para explicar la diferencia entre análisis e interpretación: el trabajo de la hermenéutica comienza justo cuando la semiótica ha terminado el suyo.]

\section{BIBLIOGRAFÍA}

Agamben, G. (2018). Karman. Breve tratado sobre la acción, la culpa y el gesto. Adriana Hidalgo editora.

Fontanille, J. (2001). Semiótica del discurso. Universidad de Lima, Fondo Editorial.

Fontanille, J. (2014). Prácticas semióticas. Universidad de Lima, Fondo Editorial.

Landowski, E. (2007). Presencias del otro. Universidad de Lima, Fondo Editorial.

Ribeyro, J.R. (1973). El banquete. En La palabra del mudo (tomo I, pp. 111-115). Carlos Milla Batres Editor.

Zilberberg, C. (2015). La estructura tensiva. Universidad de Lima, Fondo Editorial. 